\title{
The Possibilities and Pitfalls of Humanitarian Drones
}

\author{
John R. Emery
}

W hat comes to mind when we hear the word "drone"? For many of us, it is the image of a General Atomics MQ-1B Predator drone launching a Hellfire missile at a suspected militant target. But is this picture beginning to change? Should this picture change?

As technology and innovation advance, some see a more benevolent side to drones. For instance, the "PARS lifeguard," designed by Amin Rigi of RTS Lab in Iran (now London-based), is an octocopter drone that drops off lifesaving tubes that can reach a drowning victim four times faster than a lifeguard. Similarly, the "ambulance drone," developed by graduate student Alec Momont at TU Delft, Netherlands, is an autonomous quadcopter drone that carries a defibrillator for patients in cardiac arrest with a webcam link to an emergency operator to give instructions. And in February 2015 the United Arab Emirates awarded a \$1 million prize in its "drones for good" competition to the "Gimball" collisiontolerant drone, designed by the Swiss-based Flyability, which has the ability to enter burning buildings through an opening as small as one foot and can provide a live video-feed assessment to locate victims.

Innovative drones such as these can provide many benefits. But there are important tensions associated with drone technology, even in their humanitarian uses. While scholars and the public alike have focused on the controversial CIA targeted killing programs in Yemen and Pakistan, "humanitarian drones" have quietly made their way into the hands of practitioners globally. At the same time, discussion of humanitarian drones has been largely eclipsed by the immense legal and ethical dilemmas that armed drones present. Nonetheless, the groundbreaking work of Kristin Bergtora Sandvik and Kjersti Lohne of the Peace Research Institute, Oslo, has paved the way for an emerging small body of

Ethics \& International Affairs, 30, no. 2 (2016), pp. 153-165.

(C) 2016 Carnegie Council for Ethics in International Affairs

doi:10.1017/So892679415000556 
literature on humanitarian drones (which as of yet tends to focus on issues of peacekeeping). ${ }^{1}$

Drones come in a great many shapes, sizes, and capacities. Depending on their specific applications, they are known as unmanned aerial vehicles (UAVs), unmanned vehicle systems (UVSs), and unmanned aerial systems (UASs). Whatever one prefers to call them, their growing presence in endless aspects of life-commercial delivery, policing, environmental monitoring, anti-poaching efforts, and aid delivery, to name only a few-indicates that drones are undeniably here to stay. UAVs are truly multipurpose machines, meaning their humanitarian attributes largely depend on who is using them and in what manner. I take "humanitarian assistance" to mean aid and actions designed to save lives, alleviate suffering, and protect and maintain human dignity. This assistance can occur both during and in the aftermath of man-made crises and natural disasters, and also be oriented toward strengthening preparedness for such situations. Humanitarian drones are unarmed UAVs utilized by organizations-and potentially statesthat actively and consistently pursue such ends.

\section{Humanitarian Drones: The Basics}

\section{Drone Designs}

The major advantage of small humanitarian drones is that they are cheap, easy to operate, and require little logistical infrastructure on the ground. Among these smaller drones, there are two main types. First, there are small, lightweight, fixed-wing drones with a single propeller that can carry no payload. One such drone is the senseFly eBee RTK drone (cost: about \$25,000). The company senseFly was founded in 2009 by a group of robotics researchers in Lausanne, Switzerland, and is now an industry-leading producer of topographic mapping drones. ${ }^{2}$ The eBee is made of durable foam, carbon, and composite parts; weighs a mere 1.6 pounds; and has a wingspan of just 38 inches. It is battery operated, capable of flying for 40 minutes at 25 to 56 miles per hour, and is autonomous in the sense that one need simply map the area it is to survey on a computer or tablet and it is ready to take off.

The second type of smaller drones, quadcopter drones (with four helicoptertype rotors) and even octocopter variations, usually have the capacity for a video-feed camera and a small payload of a few pounds. The Matternet ONE (cost: $\$ 5,000$ ) is a battery-operated quadcopter drone from a California-based 
tech start-up company. Matternet drones can travel 12.4 miles while carrying a payload of up to 2.2 pounds without needing to recharge. ${ }^{3}$ They can be controlled via a smartphone app by selecting a destination on a map and pressing "send."

These small drones are primarily used in the private sector for surveying, agriculture, and mining purposes. However, their capabilities have proven transferable to the humanitarian sector. The eBee RTK drone, for example, has become a useful part of humanitarian efforts for survey-grade $3 \mathrm{D}$ mapping (with detailed accuracy down to a few centimeters), while the Matternet drone has been employed by the World Health Organization (WHO) and Doctors Without Borders/Médecins Sans Frontières (MSF) to transport medical supplies. Their use is circumscribed by their typically limited payload capacity, battery life, and coverage area when compared to larger drones, along with an inability to operate in adverse weather conditions.

Many larger drones that have been used for humanitarian missions were created for the defense industry, but have since been repurposed. These drones can fly for a long time at high altitudes, be operated from greater distances, and possess heavy payload capacity, which means they can be equipped with high-tech infrared cameras and radar equipment. One example is the FALCO, a drone made by the Italian company Selex ES (a subsidiary of the defense group Finmeccanica), which has been employed in the UN peacekeeping mission in the Democratic Republic of the Congo (DRC). The single-propeller FALCO has a 23.6-foot wingspan, a medium endurance of 8 to 14 hours, and a medium altitude of 16,500 feet. It can carry a payload of 154 pounds and is controlled by an on-the-ground human operator anywhere within a 125-mile range. The cost of a FALCO is \$52 million, and they have been contracted out for use by the United Nations in the DRC at a cost of $\$ 13$ million per year.

Another example is the Northrop Grumman RQ-4B Global Hawk surveillance drone, which has been used for aerial reconnaissance in disaster relief missions in Haiti and the Philippines. This huge, unmanned, remotely piloted vehicle has a wingspan of 130.9 feet, is 47.6 feet in length, can carry a 3,000-pound payload, and can fly for over 32 hours at an altitude of 65,000 feet. The aircraft itself costs roughly $\$ 123$ million to purchase and about $\$ 15,000$ per flight hour in operating costs (down from $\$ 32,000 /$ hour in 2012). ${ }^{4}$ The use of such large drones is limited mainly by operation costs and vast logistical necessities-and (as we will see below) by their perceived link with problematic military uses. 


\section{Applications of Humanitarian Drones}

The use of drones for humanitarian purposes currently falls into two broad areas: disaster prevention and relief and global health. As unarmed drones are increasingly used in peacekeeping for such tasks as surveillance, humanitarian organizations face a dilemma of how and whether to use their capacities for humanitarian tasks related to peacekeeping situations.

Disaster prevention and relief UAVs can assist in coordinating on-the-ground rescue efforts and disaster risk assessments. The eBee, for example, has already flown a number of humanitarian missions. In March 2014 the Swiss nonprofit Drone Adventures used eBees to assist the Philippines with a post-disaster needs assessment following the devastation caused by Typhoon Haiyan in November 2013. ${ }^{5}$ The data gathered provided local leaders and humanitarian organizations with detailed maps and damage assessments so as to coordinate relief efforts more quickly and efficiently. In Haiti, Drone Adventures used eBees in 2013 to enhance flood preparation and prevention by identifying potential danger zones. As a result of this effort, officials learned that a busy open-air market had been built directly in a dried-up riverbed, which necessitated the construction of protective infrastructure to avoid a future catastrophe. ${ }^{6}$ Also in 2013, as part of the reconstruction efforts following the 2010 earthquake in Haiti, the International Organization for Migration teamed up with Drone Adventures to assess destroyed houses, take a census of public buildings and hospitals, and monitor camps for internally displaced persons. ${ }^{7}$ SenseFly's larger vision is that humanitarian organizations using the eBee can multiply the effects of their work by distributing their drone-generated maps more widely-for example, through the United Nations Office for the Coordination of Humanitarian Affairs (OCHA)-to other aid workers in the area so as to ensure that they work from the same up-to-date geo-information. ${ }^{8}$ Humanitarian organizations have become well aware of the potential of the senseFly eBee. A June 2014 OCHA paper praised the eBee's work in Haiti as part of a larger analysis of humanitarian drones. ${ }^{9}$

Humanitarian drones can also be of assistance in pressing areas of global public health. For example, there are aid-delivery UAVs that transport lightweight payloads such as medical tests, vaccines, or medications to rural and inaccessible areas. Such drones have been used in Papua New Guinea, for example, which is plagued by some of the world's highest rates of tuberculosis (TB) and suffers the additional burden of its population being dispersed in remote communities linked by roads that are often impassable. Organizations such as MSF are seeking 
to help these communities administer treatment in a reasonable time, a task for which drones provide an attractive solution.

The Matternet ONE began flying with MSF in April 2014, transporting patient saliva samples from rural areas to TB testing facilities at larger hospitals, and then sending the test results back. Hence, what used to take weeks due to inadequate or damaged infrastructure can now be done in a few hours. The goal of MSF is ultimately to have a network of these drones so that everything from TB specimen samples, to blood tests, to small doses of vaccines could be sent to isolated communities in a fraction of the time it would take by land. After the initial testing stages showed promising results, the MSF began expanding the drone network to the capital region of Port Moresby throughout 2015. ${ }^{10}$ Moreover, impressed with these positive results, the Bhutanese government and WHO invited Matternet to demonstrate how they could assist those who live in that country's steep mountains and valleys. ${ }^{11}$ Nonetheless, while medical transport drones are extremely efficient and cost-effective in testing TB and sending small amounts of medical supplies, their potential remains limited by their size and design, meaning they will probably not replace helicopters for larger essentials deliveries.

Finally, unarmed drones have the ability to assist in peacekeeping measures, but here their usage is far more controversial. Technically, they have the capacity to assist in coordinating peacekeeping troops on the ground, monitoring cease-fire agreements, acting as a neutral third-party observer, and helping to dispel rumors that may incite inter-ethnic violence. The Sentinel Project, a Canadian-based nonprofit, has deployed drones in the conflict-prone Tana Delta region in Kenya in order to investigate reports of conflict and verify information about (real or rumored) impending violence. ${ }^{12}$ As much of the violence in the region has been caused by the spread of misinformation, their hope is that information gleaned from the quadcopter drones will assure residents of the region of the accuracy of the information they are acting on. Nevertheless, OCHA cited this case among others as a problematic use of drones in conflict settings, given that drones are dual-use technologies even the smallest of which can be weaponized and given that civilian populations are unable to distinguish unarmed from armed drones. ${ }^{13}$

\section{Challenges for Humanitarian Drones}

Drones have been brought into the realm of humanitarianism both by technicians offering problem-solving tools and through a concerted effort by the defense- 
dominated UAV industry, but the diverging motives of these actors create a number of tensions and challenges.

\section{The Advocacy Concern}

The main lobbying organization for drones is the Association for Unmanned Vehicle Systems International (AUVSI), a trade organization composed of more than four hundred companies and organizations that manufacture robotics and their components, as well as businesses that plan on using drones in the future. The majority of AUVSI members-including General Atomics, Airbus, Boeing, Google, Lockheed Martin, Northrop Grumman, Raytheon, and UAV Solutions-are part of the defense and security industries. AUVSI defines itself as

the leading global organization representing the views of the unmanned systems and robotics community. On behalf of our membership we are committed to shaping global policy by advocating on behalf of the unmanned systems and robotics community, monitoring legislation and assessing the global impact of the industry to ensure that obstacles to advancing and fielding unmanned systems and robotics are removed. ${ }^{14}$

In an effort to gain a share of the profits from the emerging humanitarian drone market, the drone lobby has made an explicit effort to blur the lines between military and civilian use. For the moment, however, the small tech firms remain far more cost-effective, as many defense companies still primarily manufacture larger, far more costly drones with heavier payload capacity. Nonetheless, the enormous potential of the market makes it unlikely that the big players will remain marginal for much longer. AUVSI recognizes that the public associates "drones" with targeted killings, and it is actively seeking to soften this image by using the less threatening-sounding appellation "unmanned vehicle systems" (UVS). In fact, when the president of AUVSI, Michael Toscano, testified before the Senate Judiciary Committee, he instructed the senators that he does not use the term "drone" as it "carries with it a hostile connotation." 15

The effort to destigmatize drones has important policy and ethical implications. Allegedly, the trade group has had some success in lobbying to influence drone regulation in the United States. A leaked AUVSI PowerPoint presentation for their June 2011 summit shows how the association envisions its role. In the presentation, the authors claim that as a result of their "advocacy efforts . . the only changes made to the UAS sections of the House FAA bill were made at the request of AUVSI. Our suggestions were often taken word-for-word." ${ }^{16}$ They also discuss how, once drones are granted more access to airspace, "the civil market has the 
potential to eclipse the defense market." Of course, as the presentation notes, this is contingent on "Global Conflict-particularly U.S. and allied nation involvement in future conflicts" that will "either positively or negatively" influence "market growth" for the industry. ${ }^{17}$

\section{Compromising Neutrality}

One of the main principles of humanitarianism is to maintain neutrality. This principle can be compromised if drones are perceived-even if incorrectly-to be somehow linked to a military power that has a specific stake in the conflict or humanitarian crisis. The problem is especially pronounced if the drones being used are repurposed military ones or if they are used simultaneously for humanitarian and military information gathering in the same setting-a scenario that is becoming more likely as peacekeepers start to adopt drones in both the military and civilian aspects of their missions. This issue was a key concern in the OCHA policy paper, as the impact of drones on humanitarian missions is predicated upon the perception of their use by the local community and those involved in the conflict, not the intention of the mission per se. ${ }^{18}$

Hervé Ladsous, the head of UN peacekeeping, is a proponent of the use of surveillance drones. In an effort to assist the record number of soldiers deployed on UN missions, he has called on the United Nations to upgrade its technology. As Ladsous stated, "We do need [drones] in countries like Mali, like Central African Republic and clearly in South Sudan. It would be my desire that we might deploy them .... Clearly, we cannot continue to afford to work with twentieth-century tools in the twenty-first century." ${ }^{\prime 19}$ The United Nations has already deployed drones in support of its peacekeeping mission in the Democratic Republic of the Congo, and also in Mali and along the Sudanese borders with Chad and the Central African Republic.

The challenges of such use have been clearly demonstrated in the case of the DRC, a country larger than Western Europe that is engaged in the longest running civil war in history. In 2006 the European Union deployed four surveillance drones for the UN peacekeeping mission there. One of these was shot down and another crashed, killing one person and injuring several others. ${ }^{20}$ The UN stabilization mission in the DRC (MONUSCO) deployed two more surveillance drones in December 2013 and April 2014, with three additional drones added later as a part of a UN private military contract with the Italian company Selex ES. 
While the use of drones by MONUSCO (a party to the conflict) presents challenges of its own, MONUSCO's offer to share its drones platforms with the humanitarian community for information gathering created controversies of a different order. The offer elicited a strong pushback from the aid community operating on the ground in the DRC. In July 2014 a joint international nongovernmental organization (INGO) position paper was issued by the North Kivu Chef de Mission forum on the humanitarian use of drones. It cautioned humanitarian organizations against using information gathered by UAVs, as such use blurred the lines between military and humanitarian objectives. ${ }^{21}$ The paper was critical of MONUSCO's use of drones in part because of its lack of engagement with the population on the role of the UAVs within their broader mission, such that "communities are unaware or unclear as to the nuance of their dual-use capacity as both a military and civilian asset." Anecdotal evidence gathered by INGOs in the DRC indicated that "communities are more likely to associate the UAVs with the military components of the mission. This means that the transparency, acceptance and community engagement surrounding UAV usage in DRC is questionable."

The statement warned that "INGOs risk impeding humanitarian access and losing acceptance due to the perception of being associated with the military components of MONUSCO.” Although MONUSCO is keen to

portray the UAVs as a mission-wide asset, they are in fact (as communities believe) used primarily at this stage for information gathering by MONUSCO for military intelligence. ... This dual-use capacity is problematic as it directly threatens the humanitarian principles of neutrality, impartiality and operational independence.

Most telling of the priorities of UAV flights is that they were scheduled according to the strategic priorities of MONUSCO military components, such that data gathered by the UAVs was not necessarily focused on areas of the greatest humanitarian need. This prioritization risked skewing analysis of the population's needs and violating the principle of impartiality. The thirteen INGO signatories therefore concluded that they "define the UAVs as a MONUSCO military asset," which would "allow the use of MONUSCO military assets by humanitarian actors only as a last resort under exceptional circumstances." They urged UN humanitarian agencies to adopt a similar position on the use of drones.

Indeed, OCHA, while recognizing the potential of drones to provide a unique capacity to humanitarian actors, has expressed strong reservations about their use. 
Given the regulatory and ethical issues surrounding the use of drones in peacekeeping operations, the agency recommends that humanitarians should focus on using UAVs in natural disasters only, noting that "The use of UAVs in conflict settings is still too complex and hard to separate from military uses."22

\section{The Slippery Slope Dilemma}

Military drones are being repurposed for humanitarian missions, yet the perception that they are inextricably linked to war remains, and there is an inherent lure to arm such drones in the name of preventing atrocities. As the previous section outlined, perceptions are essential to the success or failure of humanitarian missions, and to see drones as "just a tool" or as "neutral" misses a key tension surrounding the concept of humanitarian drones.

Perhaps the most representative case of drone repurposing from military to civilian use is Northrop Grumman's RQ-4 Global Hawk, operated by the U.S. Air Force. This aircraft was instrumental in both Afghanistan and Iraq; Germany also procured the "EuroHawk" version of the RQ-4 in 2011. In 2007 the Global Hawk was first used in a nonmilitary setting, as eyes in the sky to help fight wildfires in California. That same year two Hawks were transferred from the U.S. Air Force to NASA for atmospheric research that began in 2009. Recently, the Global Hawk has also been employed in disaster relief missions. In one of its advertising brochures, Northrop Grumman gives a harrowing account of the devastation of Typhoon Haiyan and proudly describes how "help arrived from 60,000 feet above" when the Global Hawk flew the first of three critical sorties from Guam to the Philippines, where it assisted with infrastructure and damage assessments. ${ }^{23}$ This image of drones is clearly a concerted marketing strategy to "sell" these military aircraft on their redeeming qualities rather than their military applications. However, the conception of the Global Hawk as "just a tool" that can be used for humanitarian purposes is deeply problematic. Madiha Tahir, an independent journalist based in Pakistan, notes that such reimagining creates "historical amnesia about the Hawk's inextricability from war. Its main function is to marshal public support for funding a technology whose most significant buyer is the military."24

Although many every-day technologies such as radar, satellite communications, and GPS were originally developed for military use, drones present a special case. They are still widely associated with "assassinations" and controversial wars, and, since they have a panoptic capability, they raise important questions about 
privacy. Again, the key is that even if the perception of drones as military machines is changing for many, it remains resilient and problematic for those on the ground in conflict zones.

Notwithstanding, there has been a significant shift in the academic debate concerning the potential for "drones for good" or "drones to protect" that is in need of critical reflection. In a recent article entitled "Drones to Protect," David Whetham envisions deploying unarmed drones to conflict zones as "flying cameras," with the intent to record and ultimately prosecute human rights violations. ${ }^{25} \mathrm{He}$ views this option as a kind of viable middle ground between doing nothing in the face of gross human rights violations and undertaking a military intervention. Whetham suggests that these UAVs could be deployed under a UN Security Council resolution, with any footage of human rights violations to be passed on to the International Criminal Court as grounds for indictment and prosecution. Although recognizing some political hurdles and military practicalities, he cites the ethically problematic MONUSCO deployment of drones in the DRC as a demonstration of the potential capabilities of UAVs. Whetham concludes that the possibility that employing such drones could restrain future perpetrators of human rights atrocities is "more than enough to justify trying this low-cost, non-invasive option on behalf of the international community." 26

There are many issues with such an argument, notably the risk to neutrality discussed above. Perhaps most obvious, however, is the slippery slope between merely deploying surveillance drones and arming them. How many atrocities would have to be witnessed and documented until one could no longer stand idly by watching violations unfold and thus push for armed drones? Why just witness a mass atrocity with limited surveillance drones when one could presumably prevent it with armed drones? One must not forget that the U.S. targeted killing program began as "flying cameras" over the Balkans and then over Afghanistan tracking Osama bin Laden before 9/11. However, after 9/11 these "flying cameras" were armed and redeployed as weapons that could track and eliminate suspected terrorists and militants even outside declared war zones.

\section{The Missing "Human" Element}

The most important advantage of drones-that they can be operated from a safe distance-may at the same time undermine their humanitarian potential. Those who view technology simply as a problem-solving tool often miss the crucial human element that is necessary to understand and adapt to complex and 
frightening situations. This is especially true in humanitarian settings, where the trust of the local population is indispensable to the success of the humanitarian effort. A key case in point is the recent Ebola outbreak.

The fear that the Ebola outbreak in Guinea, Liberia, and Sierra Leone generated in the West gave rise to wild speculation about the potential role of "Ebola drones" and other Ebola-fighting robotics, with proposals ranging from the seriously misguided to the absurd. It was suggested that "mortuary robots" that could "respectfully transport the deceased"-robots currently employed by the Tokyo fire department-would solve the problem of how to remove the dead without becoming infected. ${ }^{27}$ Furthermore, there were calls that the United States could use its military Global Hawk reconnaissance drone, based in Niger, to look for unusual human behavior, like a sudden vehicle exodus or overcrowded hospitals, which might suggest an outbreak before it is reported. ${ }^{28}$

The absurdity of such propositions becomes clear when one considers stories of actual efforts on the ground, like that of Manjo Lamin, who works with one of Sierra Leone's disease surveillance teams. In a special on the Ebola outbreak, PBS's Frontline followed Lamin, whose job was to find victims and bring them to the MSF hospitals. Lamin and his colleagues initially wore protective suits when entering local villages, but the suits "terrified the villagers, who ran, hid, and sometimes attacked them." ${ }^{29}$ Consequently, Lamin's team began to arrive in plain clothes and simply tried to keep their distance from infected patients, putting themselves at risk so as not to alarm the population and to keep patients from hiding and possibly infecting their families. One can only imagine what the response would have been to robots "respectfully gathering up corpses" and drones hovering overhead looking for "unusual human behavior."

Notwithstanding the ways such use of drones would violate local cultural rituals related to death, it might also produce a counterproductive effect in terms of controlling the spread of the virus. Given the fear that was present throughout the outbreak, drones themselves might have driven people inside, thereby likely multiplying the number of infected, instead of containing the highly contagious disease. In this scenario, the result could plausibly have been that drones would have transferred the risk from aid workers-who would be operating from a safe space-to fearful locals. The moral upshot is that when problem solving is technologically driven, that is, when humanitarian crises are viewed through the lens of the advantages of drones, the human element that is so key to 
humanitarianism (the trust between aid workers and locals) is lost, and the agency of those the technology is aiming to help is denied.

\section{LOOKING FORWARD}

The debate about drones has been slow to shift from targeted killings to the emerging category of the humanitarian drone. Looking forward, governments and organizations must be cognizant of the impending pitfalls of an overreliance on technological innovation, and must proceed with caution in the acquisition and utilization of humanitarian drones.

Drones, however, clearly possess immense humanitarian potential. But in order to alleviate some of the tensions described above, constant on-the-ground community engagement, assessment, and reassessment remain necessary. Ultimately, drones are here to stay; yet the future of the human in "humanitarian" remains more essential than ever before, as technology can never replace the situational awareness and caring power of humanitarian workers.

\section{NOTES}

${ }^{1}$ Kristin Bergtora Sandvik and Kjersti Lohne, "The Rise of the Humanitarian Drone: Giving Content to an Emerging Concept," Millennium-Journal of International Studies 43, no. 1 (2014), pp. 145-64. On lethal drones, see Rosa Brooks, "Drones and the International Rule of Law," Ethics \& International Affairs 28, no. 1 (2014), pp. 83-103.

${ }^{2}$ In order to avoid excessive citations, all expository information gathered concerning the technical details of UAVs and companies producing them has been retrieved from the company websites unless otherwise cited.

${ }^{3}$ Jason Dorrier, "Pilots Need Not Apply: Matternet Launches Autonomous Drone Delivery System," Singularity $H U B$, April 7, 2015, singularityhub.com/2015/04/07/pilots-need-not-apply-matternetlaunches-autonomous-drone-delivery-system/.

${ }^{4}$ See Joakim Kasper Oestergaard Balle, "About the RQ-4B \& MQ-4C," Aeroweb, June 8, 2015, www.bgaaeroweb.com/Defense/RQ-4-Global-Hawk.html; and Aaron Mehta, "USAF Looks to Global Hawk Upgrades," Defense News, March 7, 2015, www.defensenews.com/story/defense/air-space/isr/2015/03/07/global-hawk-looks-to-future-upgrades/24120821/.

5 Adam Klaptocz, "Mapping the Philippines After Typhoon Haiyan," Drone Adventures website, May 2014, blog.droneadventures.org/post/85863359885/mapping-the-philippines-after-typhoon-haiyan.

6 Emanuele Lubrano, "What Drone-Sourced Maps Have Brought to Haiti," Drone Adventures website, July 2014, blog.droneadventures.org/post/91252234110/what-drone-sourced-maps-have-brought-tohaiti.

7 OCHA, Unmanned Aerial Vehicles in Humanitarian Response (Policy Development and Studies Branch, June 2014).

8 "Drones For Humanitarian Aid," senseFly website, www.sensefly.com/applications/humanitarian.html.

9 Ibid.

10 "Innovating to Fight Tuberculosis in Papua New Guinea," Doctors Without Borders website, November 14, 2014, www.doctorswithoutborders.org/article/innovating-fight-tuberculosis-papua-new-guinea.

${ }^{11}$ Esha Chhabra, "Drones for Good: Projects From Around the World on How Drones Can Help Us," Forbes, February 27, 2015.

12 Drew Boyd, "Humanitarian Drones: Perceptions vs. Reality in Kenya's Tana Delta," Sentinel Project website, November 18, 2014, thesentinelproject.org/2014/11/18/humanitarian-drones-perceptionsvs-reality-in-kenyas-tana-delta/.

13 OCHA, Unmanned Aerial Vehicles in Humanitarian Response. 
14 "Issues \& Policy," AUVSI website, www.auvsi.org/auvsi/advocacy/ (accessed May 24, 2015).

15 "The Future of Drones in America: Law Enforcement and Privacy Considerations. Hearing Before the Committee on the Judiciary, United States Senate," $113^{\text {th }}$ Congress, First Session, March 20, 2013, www. judiciary.senate.gov/imo/media/doc/CHRG-113shrg81775.pdf.

${ }^{16}$ A full copy of the leaked AUVSI PowerPoint presentation is available at www.republicreport. org/2012/drone-powerpoint-lobby-plan/.

17 Ibid.

${ }^{18}$ OCHA, Unmanned Aerial Vehicles in Humanitarian Response.

19 "UN Peacekeeping Chief Wants More Drones," Al Jazeera, May 30, 2014, www.aljazeera. $\mathrm{com} /$ news/africa/2014/05/un-peacekeeping-chief-wants-more-drones-201453045212978750.html.

${ }^{20}$ John Karlsrud and Frederik Rosén, "In the Eye of the Beholder? UN and the Use of Drones to Protect Civilians," Stability: International Journal of Security \& Development 2 no. 2 (2013), www.stabilityjournal.org/article/view/94.

21 "Joint INGO Position on Humanitarian Use of UAVs," ReliefWeb, July 16, 2014, reliefweb. int/report/democratic-republic-congo/joint-ingo-position-humanitarian-use-uavs.

${ }^{22}$ OCHA, Unmanned Aerial Vehicles in Humanitarian Response.

${ }^{23}$ Elizabeth Malloy, "Relief From Above," Inside Aerospace (April 2014), www.northropgrumman. com/Capabilities/GlobalHawk/Documents/Relief_From_Above.pdf.

${ }^{24}$ Madiha Tahir, “The Drone Lobby's Image Problem," Al Jazeera, March 22, 2014, www.aljazeera. com/indepth/opinion/2014/o2/drone-lobby-image-problem-2014225114616766109.html.

25 David Whetham, "Drones to Protect," International Journal of Human Rights 19, no. 2 (2015), pp. 199-210.

26 Ibid., p. 208.

${ }^{27}$ Patrick Tucker, "Here Are Some Robots We Could Use to Fight Ebola in Africa," Defense One, October 21, 2014, www.defenseone.com/technology/2014/10/here-are-some-robots-we-could-use-fight-ebolaafrica/97100/.

${ }^{28}$ Kelsey D. Atherton, "The Week in Drones: Drones Fight Ebola, Iranian Dogfighters, and More," Popular Science, September 26, 2014, www.popsci.com/article/science/week-drones-drones-fightebola-iranian-dogfighters-and-more.

29 "Ebola Outbreak," PBS Frontline, September 9, 2014, www.pbs.org/wgbh/frontline/film/ebolaoutbreak/. 